\title{
Review Article \\ Outcomes of Endoscopic-Ultrasound-Guided Cholangiopancreatography: A Literature Review
}

\author{
Shahzad Iqbal, David M. Friedel, James H. Grendell, and Stavros N. Stavropoulos \\ Department of Medicine, Division of Gastroenterology, Winthrop University Hospital, Mineola, NY 11507, USA \\ Correspondence should be addressed to Shahzad Iqbal; siqbal50@gmail.com
}

Received 27 January 2013; Revised 19 February 2013; Accepted 20 February 2013

Academic Editor: Everson L. A. Artifon

Copyright ( 2013 Shahzad Iqbal et al. This is an open access article distributed under the Creative Commons Attribution License, which permits unrestricted use, distribution, and reproduction in any medium, provided the original work is properly cited.

\begin{abstract}
Endoscopic retrograde cholangiopancreatography (ERCP) can fail in 3-10\% of the cases even in experienced hands. Although percutaneous transhepatic cholangiography (PTC) and surgery are the traditional alternatives, there are morbidity and mortality associated with both. In this paper, we have discussed the efficacy and safety of endoscopic-ultrasound-guided cholangiopancreatography (EUS-CP) in decompression of biliary and pancreatic ducts. The overall technical and clinical success rates are around $90 \%$ for biliary and $70 \%$ for pancreatic duct drainage. The overall EUS-CP complication rate is around $15 \%$. EUS$\mathrm{CP}$ is, however, a technically challenging procedure and should be performed by an experienced endoscopist skilled in both EUS and ERCP. Same session EUS-CP as failed initial ERCP is practical and may result in avoidance of additional procedures. With increasing availability of endoscopists trained in both ERCP and EUS, the role of EUS-CP is likely to grow in clinical practice.
\end{abstract}

\section{Introduction}

Endoscopic retrograde cholangiopancreatography (ERCP) is the standard procedure for decompression of biliary and pancreatic ducts. Although the success rate is very high, it can fail in 3-10\% of cases even by an experienced endoscopist $[1,2]$. Percutaneous transhepatic cholangiography (PTC) $[3$, $4]$ and surgery $[5,6]$ have been the traditional alternatives. However, there is morbidity and mortality associated with both. PTC has a complication rate of up to $30 \%$ [4]. Although surgery offers long-term patency, it is also associated with increased morbidity as well as mortality [6]. Since first reported by Wiersema et al. [7], endoscopic ultrasound guided cholangiopancreatography (EUS-CP) is now increasingly being employed at expert centers as an alternative to surgery or PTC.

An online pubmed search was conducted to review the published case reports and series on EUS-CP. The key words used were endoscopic-ultrasoundguided cholangio-pancreatography, endoscopic-ultrasoundguided cholangiography, endoscopic-ultrasound-guided pancreatography, failed endoscopic retrograde cholangiopancreatography, endoscopic-ultrasound-guided therapeutic interventions, endoscopic-ultrasound-guided biliary drainage, and endoscopic-ultrasound-guided pancreatic drainage. All studies and case series involving at least 5 patients were included for the present review. The purpose of this paper was to analyze the published data on EUS-CP and assess its overall efficacy and safety in decompression of biliary and pancreatic ducts. First the indications and techniques of EUS-CP will be discussed, followed by efficacy, safety, and role in clinical practice.

\section{Indications of EUS-CP}

The first case series of EUS-guided cholangiogram was reported by Wiersema et al. in 1996 [7]. Biliary drainage has been performed for both malignant as well as benign indications. The reported malignant biliary indications were pancreatic cancer, metastatic cancer, cholangiocarcinoma, gallbladder cancer, ampullary cancer, and duodenal cancer. Following were the benign biliary indications: bile leak, benign strictures (PSC or iatrogenic), choledocholithiasis, and papillary stenosis. The reported pancreatic indications were pancreas divisum, benign pancreatic duct strictures (chronic pancreatitis, postsevere acute pancreatitis), postsurgical (Whipple) pancreaticojejunostomy stricture, pancreatic 
stone with obstruction, pancreatic leak \pm fistula, and papillary stenosis. The pancreatic duct was dilated $(>4 \mathrm{~mm}$ in diameter) in most of the studies. However, the nondilated duct was also accessed in recent studies [8]. Initially, EUS-CP was performed on a subsequent day after failed initial ERCP. However, there was a trend towards same day/session EUS$\mathrm{CP}$ with recent studies [9].

In general, EUS-CP can be considered in patients with native papilla after failed initial ERCP or inaccessible papilla due to either obstructed gastrointestinal tract lumen or surgically altered anatomy. The procedure is especially helpful in altered anatomy cases after failed initial ERCP like post-Whipple, Billroth II gastrojejunostomy, hepaticojejunostomy, gastric bypass, and duodenal switch. The bile duct can be accessed by either an extrahepatic or intrahepatic approach. The decision between the extrahepatic and intrahepatic approach is based on the following factors: presence of intrahepatic dilation, presence of gastric outlet obstruction, and ability to reach the second part of duodenum.

\section{Technique}

3.1. Patient Selection and Preparation. All such cases should be performed in a tertiary care center by an experienced endoscopist who is proficient in both ERCP and EUS. Repeat ERCP should be attempted on patients referred to the tertiary care center before resorting to EUS-CP. The failed ERCP was defined as failed deep access to bile or pancreatic duct despite the use of advanced cannulation techniques including precut sphincterotomy [10]. The procedure should be done in a dedicated interventional endoscopy room equipped with both fluoroscopy and EUS capability. An informed consent explaining the risk and benefits of EUS-CP versus PTC and surgery needs to be explained to the patient. Prophylactic antibiotics should be administered. Since EUS$\mathrm{CP}$ is a longer procedure, anesthesia assistance should be sought. In the published data, all such cases were done either under intravenous sedation or general anesthesia. It is also important to have back up of both surgical and interventional radiology services.

3.2. Instruments and Accessories Selection. The procedure is done using a curvilinear array echoendoscope, preferably therapeutic with working channel of over $3 \mathrm{~mm}$. The following therapeutic echoendoscopes are commonly used in the United States: GF-UCT140 (Olympus America Inc, Center valley, PA, USA) and EG-3870UTK (Pentax of America Inc, Montvale, NJ, USA) with working channels of 3.7 and $3.8 \mathrm{~mm}$, respectively. These allow placement of stents up to 10 Fr (French) in diameter (Table 1).

A 19- or 22-gauge FNA (fine needle aspiration) needle is used for initial duct puncture. A $5 \mathrm{Fr}$ needle knife or 19-gauge fistulotome can also be used for duct puncture. One of the following long ( 450 or $480 \mathrm{cms}$ ) guidewires are then passed into the duct: 0.018 inch, 0.021 inch, 0.025 inch, or 0.035 inch. The 19-gauge FNA needle allows passage of all guidewires, while 22-gauge one allows only 0.018 and
TABLE 1: Instruments and accessories needed for EUS-CP.

\begin{tabular}{|c|c|}
\hline Purpose & Devices \\
\hline \multirow{3}{*}{ Echoendoscopes } & $\begin{array}{l}\text { Preferably therapeutic ( }>3 \mathrm{~mm} \text { working } \\
\text { channel): }\end{array}$ \\
\hline & $\begin{array}{l}\text { (i) GF-UCT140 (Olympus America Inc, } \\
\text { Center valley, PA, USA): } 3.7 \mathrm{~mm}\end{array}$ \\
\hline & $\begin{array}{l}\text { (ii) EG-3870UTK (Pentax of America Inc, } \\
\text { Montvale, NJ, USA): } 3.8 \mathrm{~mm}\end{array}$ \\
\hline \multirow{3}{*}{ Puncture devices } & $\begin{array}{l}\text { (i) 19- or 22-gauge fine needle aspiration } \\
\text { needles }\end{array}$ \\
\hline & (ii) 19-gauge fistulotome \\
\hline & (iii) 5 Fr needle knife \\
\hline \multirow{2}{*}{ Guidewires } & Long ( 450 or $480 \mathrm{cms})$ : \\
\hline & $\begin{array}{l}0.018 \text { inch, } 0.021 \text { inch, } 0.025 \text { inch, or } \\
0.035 \text { inch }\end{array}$ \\
\hline \multirow{6}{*}{ Dilation devices } & $\begin{array}{l}\text { Needed for transluminal and antegrade } \\
\text { techniques: }\end{array}$ \\
\hline & $\begin{array}{l}\text { (i) 6-10 Fr bougie (SBDC; (Cook Medical Inc, } \\
\text { Bloomington, IN, USA) }\end{array}$ \\
\hline & $\begin{array}{l}\text { (ii) 4-6 mm dilation balloon (Boston } \\
\text { Scientific, Natick, MA, USA) }\end{array}$ \\
\hline & $\begin{array}{l}\text { (iii) ERCP 3.9-4.9 Fr sphincterotome (Boston } \\
\text { Scientific, Natick, MA, USA) }\end{array}$ \\
\hline & $\begin{array}{l}\text { (iv) } 5.5 \text { Fr needle knife cautery (Boston } \\
\text { Scientific, Natick, MA, USA) }\end{array}$ \\
\hline & $\begin{array}{l}\text { (v) 6-8.5 Fr cystotome (EndoFlex, Voerde, } \\
\text { Germany). }\end{array}$ \\
\hline \multirow{5}{*}{$\begin{array}{l}\text { Stent types } \\
\text { (as needed) }\end{array}$} & Biliary: \\
\hline & $\begin{array}{l}\text { Plastic (6-10 Fr; straight, single, or double } \\
\text { pigtail) }\end{array}$ \\
\hline & $\begin{array}{l}\text { Metal }(8-10 \mathrm{~mm} \text {; uncovered, partially fully } \\
\text { covered })^{\#}\end{array}$ \\
\hline & Pancreatic: \\
\hline & $\begin{array}{l}\text { Plastic (5-10 Fr; straight, single, or double } \\
\text { pigtail) }\end{array}$ \\
\hline
\end{tabular}

EUS-CP: endoscopic-ultrasound-guided cholangiopancreatography. ${ }^{*}$ Needle knife cautery is associated with increased risk of postprocedure

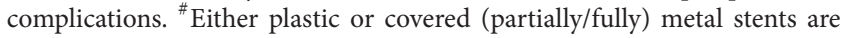
used for transluminal stenting.

0.021 inch guidewires. It is technically easier to deploy a subsequent stent over a wider diameter guidewire. However, the maneuverability is relatively better with smaller diameter guidewire. The following accessories are used for dilation of newly created fistula in selected cases (especially in transluminal and antegrade stenting): 6-10 Fr bougie (SBDC; (Cook Medical Inc, Bloomington, IN, USA)), 4-6 mm dilation balloon (Boston Scientific, Natick, MA, USA), ERCP 3.9-4.9 Fr sphincterotome (Boston Scientific, Natick, MA, USA), 5.5 Fr Needle Knife cautery (Boston Scientific, Natick, MA, USA), or 6-8.5 Fr Cystotome (EndoFlex, Voerde, Germany). The use of needle knife cautery should be avoided if possible as it was shown to be associated with postprocedure complications in a multivariate analysis by Park do et al. [11]. The rest of the accessories (including stone retrieval balloon and stents) are the same as those for conventional ERCP. 


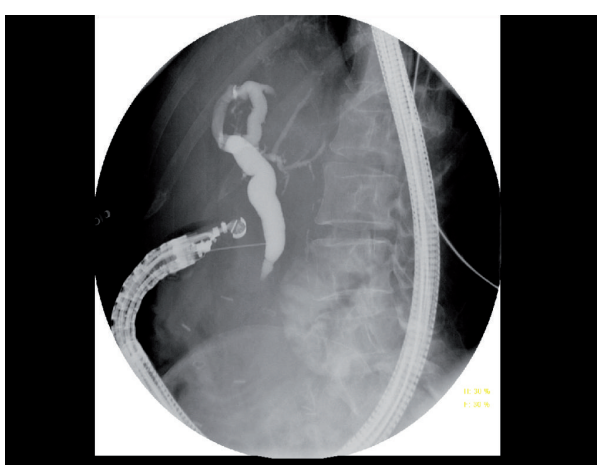

(a)

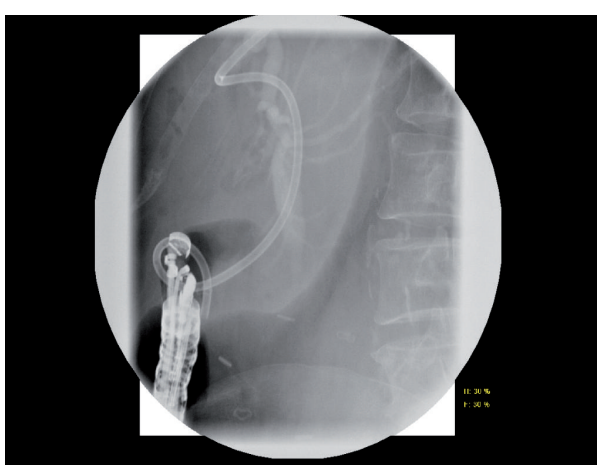

(c)

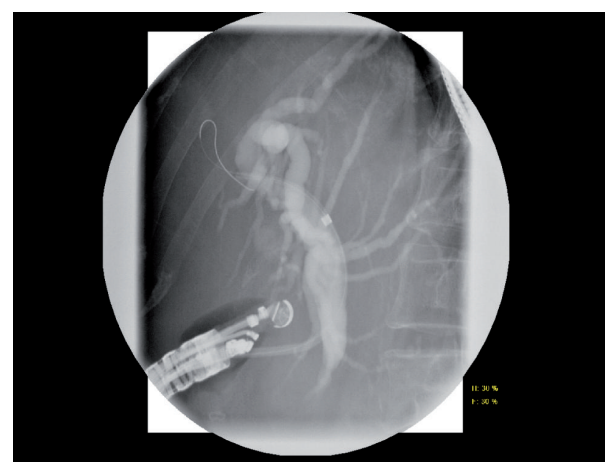

(b)

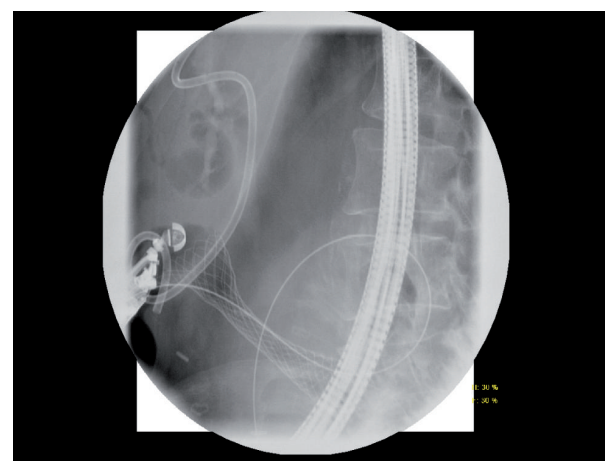

(d)

Figure 1: Transluminal stenting in a patient with metastatic breast cancer with extrahepatic biliary and duodenal obstruction. (a) Initial Cholangiogram using 22-gauge needle via transduodenal approach. (b) Choledochoduodenostomy tract dilation with 7-10 Fr dilating catheter. (c) Placement of a $10 \mathrm{Fr} \times 6 \mathrm{~cm}$ double-pigtail plastic stent. (d) Placement of a $22 \times 60 \mathrm{~mm}$ uncovered enteral stent.

\subsection{Technical Methods}

3.3.1. Biliary EUS-CP. As mentioned before, the bile duct can be accessed by either extrahepatic (transenterictranscholedochal) or intrahepatic (transgastric-transhepatic) approach. According Maranki et al. [12], the extrahepatic approach is less challenging and should be preferred when second part of duodenum is accessible.

3.3.2. Extrahepatic Biliary Tree. The echoendoscope is positioned either in the duodenal bulb or distal antrum for extrahepatic approach. Color-Doppler US is used to confirm lack of vascular structures. One of the EUS-FNA needles (as mentioned previously) is used to puncture the extrahepatic bile duct. Upon removal of stylet, the fluid is aspirated to confirm entrance of needle tip inside the duct. Contrast is injected under fluoroscopic guidance to obtain a ductogram. A long ( 450 or $480 \mathrm{cms}$ ) guidewire is passed into the bile duct. EUS-CP is then completed by one of the following techniques: ductography, rendezvous with transpapillary stenting, antegrade tract dilation/stenting, and transluminal tract dilation/stenting.

(1) Ductography: after EUS-FNA needle has been passed into the bile duct, contrast is injected. The opacified duct is then used as a guide for retrograde cannulation by a duodenoscope. It may facilitate cannulation by causing visible ampullary bulge in cases with flat intradiverticular papilla [13].

(2) Rendezvous: the EUS-FNA needle tip is oriented in a caudal direction, and attempts are made in passing the guidewire across the papilla. If successful, the echoendoscope is removed leaving the guidewire in place, with the upper end securely held near patient's mouth. A duodenoscope is passed beside the guidewire into the second part of duodenum. The guidewire is caught with a rat tooth forceps or snare and pulled through the operating channel of the duodenoscope. The rest of the procedure is completed in a retrograde ERCP fashion. Instead of catching the guidewire, biliary cannulation can also be done alongside the guidewire by passing another guidewire or sphincterotome next to it.

(3) Antegrade: if transpapillary guidewire passage is unsuccessful or papilla is not accessible, antegrade approach can be attempted. The fistula tract is first dilated (with one or a combination of previously mentioned dilation accessories), followed by antegrade placement of stent across the stricture (and possibly transpapillary, if possible). Antegrade clearance of stones can also be achieved in selected cases.

(4) Transluminal: the EUS-FNA needle tip is oriented in upward direction, and the guidewire is passed in an upward direction of the puncture. The fistula tract is dilated (with one or a combination of the previously mentioned dilation accessories), followed by transenteric-transcholedochal 


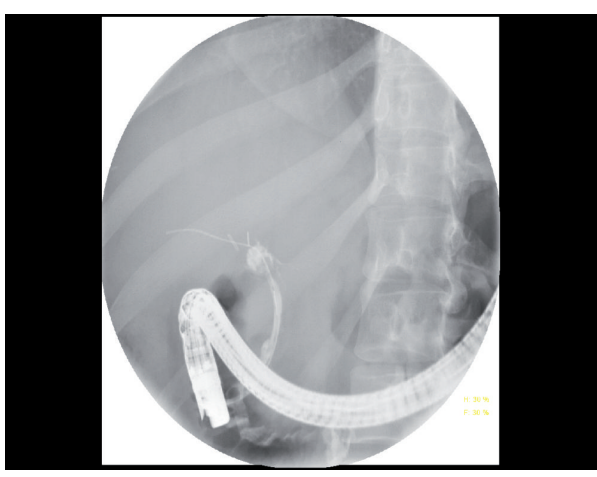

(a)

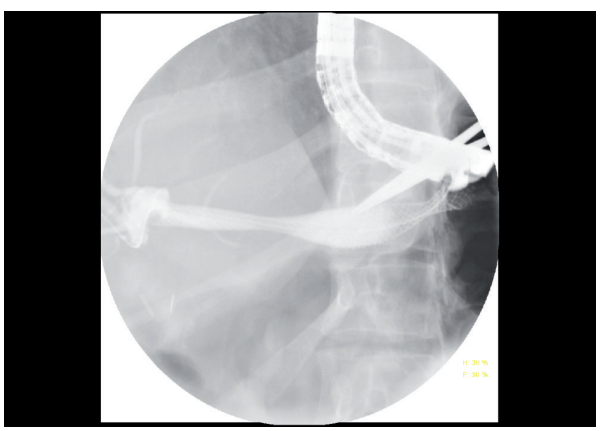

(c)

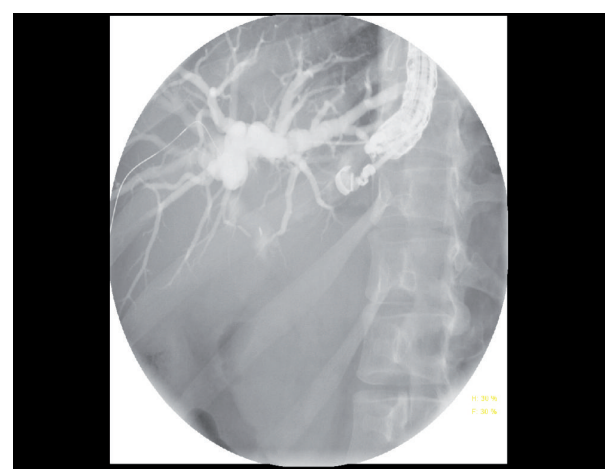

(b)

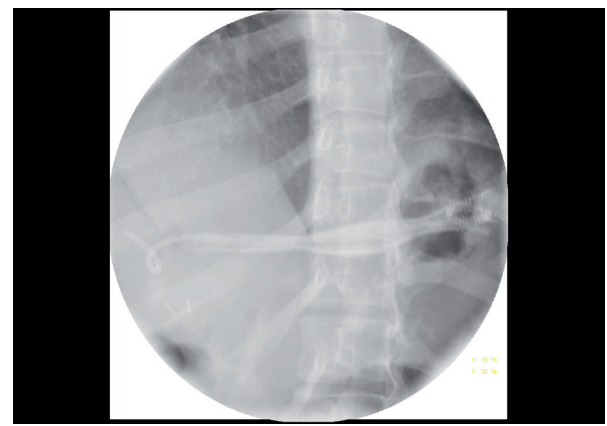

(d)

Figure 2: Transluminal stenting in a patient with common hepatic duct transection post-cholecystectomy. (a) Complete iatrogenic CHD obstruction at the site of cholecystectomy clips. (b) Initial cholangiogram with a 19-gauge needle via transgastric approach with passage of $0.025^{\prime \prime}$ guidewire. (c) Placement of two $10 \times 80 \mathrm{~mm}$ partially covered SEMS. (d) Placement of a $7 \mathrm{Fr} \times 12 \mathrm{~cm}$ double-pigtail plastic stent inside metal stents to prevent outmigration.

placement of stent(s). Unlike pancreatic pseudocyst drainage, it is important to focus on EUS and fluoroscopic views rather than endoscopic view during tract dilation and stenting. Only for the final part of stent placement, the echoendoscope is withdrawn to get endoscopic view. For metal stents, sufficient (about $2 \mathrm{cms}$ ) intraluminal length is needed to compensate for foreshortening postdeployment. It is our expert opinion that transluminal stenting is more technically challenging than other EUS-CP techniques. However, in cases where the guidewire does not cross papilla and antegrade stenting is not possible due to acute angulation, transluminal stenting is the only possibility (Figure 1).

\subsubsection{Intrahepatic Biliary Tree. The echoendoscope is posi-} tioned in the cardia or lesser curvature of stomach for intrahepatic (left liver) approach. The intrahepatic tree can also be accessed through distal esophagus [14]. One of the EUSFNA needles (as mentioned previously) is used to puncture the left intrahepatic biliary tree. The rest of the procedure is similar to that described for extrahepatic approach. During transluminal technique, attempts should be made to advance the guidewire either into the right intrahepatic ducts (if possible) or to make few intrahepatic loops in order to provide stability for subsequent tract dilation and stenting (Figure 2).
3.3.4. Pancreatic EUS-CP. The echoendoscope is positioned either in the gastric body or duodenal bulb $[13,15]$. The EUS$\mathrm{CP}$ techniques are similar to those of biliary tree. During ductography, $1 \%$ methylene blue can be mixed in 1:4 ratio with full strength contrast. Methylene blue acts as guide to the location of pancreatic duct orifice in the small intestine. The guidewire is advanced antegrade towards the papilla for rendezvous or antegrade techniques. If not possible, the guidewire is advanced retrograde and looped in the pancreatic duct for transluminal approach (Figure 3).

\section{Efficacy and Safety of EUS-CP}

4.1. Definitions. All the published case reports and series were reviewed, and studies involving at least 5 patients were included for the present review. The data was separated into extrahepatic biliary, intrahepatic biliary, and pancreatic duct drainage. The technical success was defined as the decompression of the pancreatobiliary tree with placement of a stent and/or stone extraction [13]. The clinical success was defined as resolution of jaundice, pain relief [13], or major improvement of symptoms (like resolution of pancreatic fistula) [16]. Kahaleh et al. [17] measured mean pancreatic duct size, pain scores, and weight before and after the procedure as clinical success parameters. 


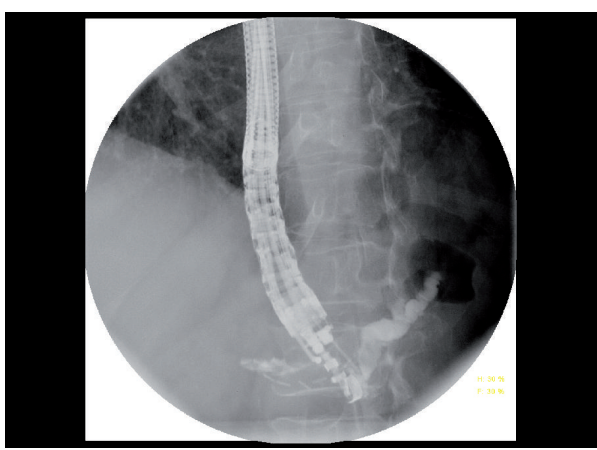

(a)

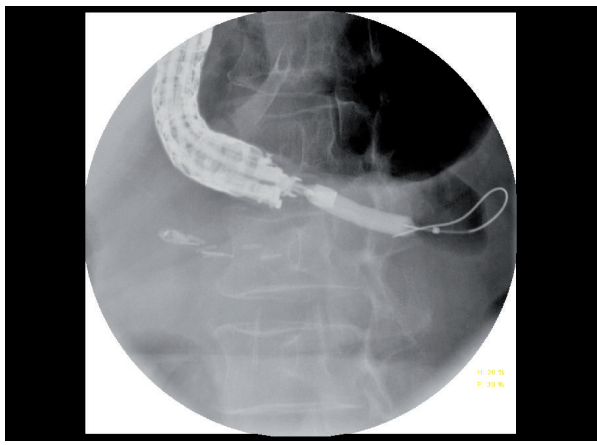

(c)

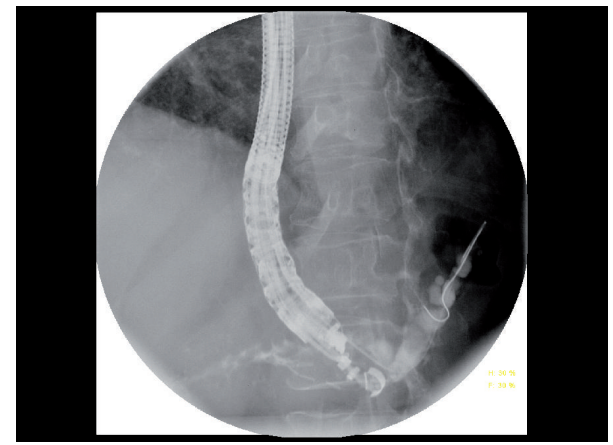

(b)

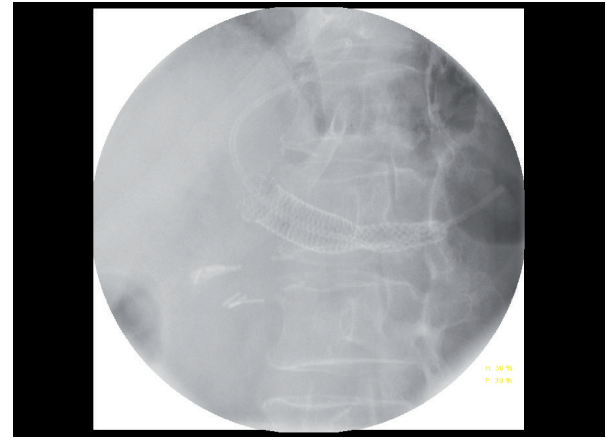

(d)

FIGURE 3: Transluminal stenting in a patient s/p central pancreatectomy with pancreaticogastrostomy obstruction. (a) Initial pancreatogram. (b) Passage of a $0.025^{\prime \prime}$ guidewire. (c) Pancreaticogastrostomy tract dilation with $6 \mathrm{~mm}$ dilation balloon. (d) Placement of a $8 \times 60 \mathrm{~mm}$ fully covered SEMS followed by $7 \mathrm{Fr} \times 7 \mathrm{~cm}$ single-pigtail plastic stents placement.

4.2. Extrahepatic Biliary Tree. Table 2 presents the published data on extrahepatic biliary drainage. There are 21 studies involving 360 on extrahepatic biliary drainage via EUSCP. The first case series of EUS-guided cholangiogram was reported by Wiersema et al. in 1996 [7]. Later, Giovannini et al. [18] reported the first case of transluminal stenting, followed by common bile duct stone removal by Püspök et al. [19]. Plastic stents were first placed transluminally to create a fistula, followed by stone removal in 3 weeks. Overall, the procedure was technically successful in $325 / 360$ cases $(90 \%$; range $70-100 \%)$.The overall clinical success (if reported) was achieved in 254/258 (98\%; range 60-100\%). The overall complication rate was $51 / 360$ cases (14\%, range $0-47 \%)$. These included pneumoperitoneum, bile leak/peritonitis, hemobilia, bacteremia, pancreatitis, abdominal pain, and cardiopulmonary failure due to fluid overload [13].

4.3. Intrahepatic Biliary Tree. The published data for intrahepatic biliary drainage is listed in Table 3 . There are 8 published studies involving 123 cases. The overall technical and clinical success rates were $109 / 23$ (88.6\%, range $44-100 \%)$ and $103 / 109$ (94.5\%, range $83-100 \%)$, respectively. The overall complication rate was $19 / 123$ (15\%, range $7.7-36 \%)$. These included pneumoperitoneum, cholangitis, bile leak, minor bleed, stent dysfunction (occlusion/migration), aspiration pneumonia, and even death from bile peritonitis due to stent migration in one patient [8].
The procedure timing was not reported by most of the studies. Kim et al. [20] reported a median procedure time of 19.5 minutes (range 14-35) for transluminal approach. In a case series of 6 patients with gastric bypass, the procedure time ranged from 66-78 minutes for antegrade and 100-144 minutes for rendezvous approaches. The stent types placed were both plastic (6-10 Fr, straight, single or double pigtail), and metal (8-10 $\mathrm{mm}$, uncovered, partially fully covered). Either plastic or covered (partially/fully) metal stents were placed transluminally. Stent dysfunction in the form of either occlusion or migration was encountered more frequently with transluminal approach. Stent dysfunction was noted in 16 out of 55 patients (29\%) in the study by Park do et al. [11], with reintervention successful in all patients with fully covered metal and in half with plastic stents. The mean stent patency was 133 days (range 18-433).

4.4. Pancreatic Duct. Table 4 shows the published data on drainage on pancreatic duct via EUS-CP. There are 6 published studies involving 115 cases. Wiersema et al. [7] reported the first case on pancreatic ductography in 1996, followed by injection of methylene blue-contrast solution by DeWitt et al. in 2004 [21] to localize minor papilla in a patient with pancreas divisum. The largest pancreatic case series of 36 patients was reported by Tessier et al. in 2007 [22]. The overall technical and clinical success (if reported) rates were 90/115 (78\%, range $48-91.7 \%)$ and 51/68 (75\%, 
TABle 2: Published EUS-CP series on Extrahepatic biliary tree drainage (involving $\geq 5$ patients).

\begin{tabular}{|c|c|c|c|c|c|c|c|c|}
\hline Year & Author & $N$ & Indication & Initial ERCP & Techniques & Technical success & Clinical success & Complication \\
\hline 1996 & Wiersema et al. [7] & 10 & B & Both & $\mathrm{D}$ & 7/10 (70\%) & $\mathrm{n} / \mathrm{a}$ & $1 / 10(10 \%)$ \\
\hline 2005 & Püspök et al. [19] & 5 & M & $\mathrm{Sb}$ & $\mathrm{T}$ & $5 / 5(100 \%)$ & $5 / 5(100 \%)$ & No \\
\hline 2006 & Kahaleh et al. [28] & 10 & Both & $\mathrm{Sb}$ & $8 \mathrm{R} ; 2 \mathrm{~T}$ & $9 / 10(90 \%)$ & $9 / 10(90 \%)$ & $3 / 9(33 \%)$ \\
\hline 2008 & Yamao et al. [29] & 5 & M & $\mathrm{Sb}$ & $\mathrm{T}$ & $5 / 5(100 \%)$ & $5 / 5(100 \%)$ & $1 / 5(20 \%)$ \\
\hline 2008 & Tarantino et al. [30] & 9 & Both & $\mathrm{Sb}$ & $4 \mathrm{~T} ; 4 \mathrm{R} ; 1 \mathrm{D}$ & 9/9 (100\%) & 9/9 (100\%) & No \\
\hline 2009 & Maranki et al. [12] & 14 & Both & Sb (mostly) & $8 \mathrm{R} ; 4 \mathrm{~T}$ & $12 / 14(86 \%)$ & $12 / 12(100 \%)$ & $3 / 14(21 \%)$ \\
\hline 2009 & Brauer et al. [13] & 12 & Both & $\mathrm{Sb}$ & $4 \mathrm{R} ; 4 \mathrm{~T} ; 3 \mathrm{D}$ & $11 / 12(92 \%)$ & $11 / 11(100 \%)$ & $2 / 12(16.7 \%)$ \\
\hline 2009 & Horaguchi et al. [14] & 8 & M & $\mathrm{Sb}$ & $\mathrm{T}$ & $8 / 8(100 \%)$ & $8 / 8(100 \%)$ & $1 / 8(12.5 \%)$ \\
\hline 2010 & Kim et al. [10] & 15 & Both & Sm (mostly) & $\mathrm{R}$ & $12 / 15(80 \%)$ & $11 / 12(91.7 \%)$ & $2 / 15(13.3 \%)$ \\
\hline 2010 & Iwamuro et al. [27] & 7 & M & $\mathrm{Sb}$ & $\mathrm{T}$ & 7/7 (100\%) & 7/7 (100\%) & $2 / 7(28 \%)$ \\
\hline 2011 & Siddiqui et al. [31] & 8 & M & $\mathrm{Sb}$ & $\mathrm{T}$ & $8 / 8(100 \%)$ & $8 / 8(100 \%)$ & $2 / 8(25 \%)$ \\
\hline 2011 & Komaki et al. [32] & 15 & M & $\mathrm{n} / \mathrm{a}$ & $14 \mathrm{~T} ; 1 \mathrm{R}$ & $15 / 15(100 \%)$ & $15 / 15(100 \%)$ & $7 / 15(47 \%)$ \\
\hline 2011 & Hara et al. [33] & 18 & M & $\mathrm{n} / \mathrm{a}$ & $\mathrm{T}$ & $17 / 18(94 \%)$ & $17 / 17(100 \%)$ & $3 / 18(17 \%)$ \\
\hline 2011 & Park do et al. [11] & 26 & Both & $\mathrm{Sm}$ & $\mathrm{T}$ & $24 / 26(92 \%)$ & $22 / 24(92 \%)$ & $5 / 26(19 \%)$ \\
\hline 2011 & Ramírez-Luna et al. [34] & 9 & M & $\mathrm{Sb}$ & $\mathrm{T}$ & $8 / 9(89 \%)$ & $8 / 8(100 \%)$ & $1 / 9(11 \%)$ \\
\hline 2011 & Fabbri et al. [35] & 16 & M & $\mathrm{Sm}$ & $13 \mathrm{~T} ; 3 \mathrm{R}$ & $12 / 16(75 \%)$ & $12 / 12(100 \%)$ & $1 / 16(6.25 \%)$ \\
\hline 2012 & Dhir et al. [26] & 58 & Both & Sm & $\mathrm{R}$ & $57 / 58(98.3 \%)$ & $57 / 57(100 \%)$ & $2 / 58(3.4 \%)$ \\
\hline 2012 & Iwashita et al. [36] & 31 & Both & $\mathrm{Sm}$ & $\mathrm{R}$ & $25 / 31(81 \%)$ & $25 / 25(100 \%)$ & $4 / / 31(13 \%)$ \\
\hline 2012 & Kim et al. [20] & 9 & M & $\mathrm{Sb}$ & $\mathrm{T}$ & 9/9 (100\%) & 9/9 (100\%) & $3 / 9(33 \%)$ \\
\hline 2012 & 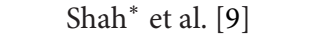 & 70 & Both & Sm & $46 \mathrm{R} ; 20 \mathrm{~A}$ (or T); $2 \mathrm{D}$ & $60 / 70(85.7 \%)$ & $\mathrm{n} / \mathrm{a}$ & $6 / 70(8.5 \%)$ \\
\hline \multirow[t]{2}{*}{2012} & Maluf-Filho et al. [37] & 5 & M & $\mathrm{Sm}$ & $\mathrm{T}$ & $5 / 5(100 \%)$ & $3 / 5(60 \%)$ & $2 / 5(40 \%)$ \\
\hline & Total & 360 & & & $178 \mathrm{R} ; 141 \mathrm{~T} ; 20 \mathrm{~A} ; 16 \mathrm{D}$ & $325 / 360(90 \%)$ & $254 / 258(98 \%)$ & $51 / 360(14 \%)$ \\
\hline
\end{tabular}

EUS-CP: endoscopic-ultrasound-guided cholangiopancreatography, $N$ : number of patients, B: benign, M: malignant, Sb: subsequent day, Sm: same day/session, D: ductography, T: transluminal, R: rendezvous, A: antegrade, n/a: not applicable/mentioned. ${ }^{*}$ The biliary tree was accessed at extra- as well as intrahepatic levels. However, the exact puncture site was not specified in the paper.

TABLE 3: Published EUS-CP series on intrahepatic (left) biliary tree drainage (involving $\geq 5$ patients).

\begin{tabular}{|c|c|c|c|c|c|c|c|c|}
\hline Year & Author & $N$ & Indication & Initial ERCP & Techniques & Technical success & Clinical Success & Complication \\
\hline 2006 & Kahaleh et al. [28] & 13 & Both & $\mathrm{Sb}$ & $11 \mathrm{R}^{*} ; 1 \mathrm{~T}$ & $12 / 13(92.3 \%)$ & $12 / 12(100 \%)$ & $1 / 13(7.7 \%)$ \\
\hline 2007 & Bories et al. [38] & 11 & Both & $\mathrm{Sb}$ & $\mathrm{T}$ & 10/11 (91\%) & $10 / 10(100 \%)$ & $4 / 11(36 \%)$ \\
\hline 2007 & Will et al. [7] & $10^{\#}$ & Both & $\mathrm{Sb}$ & $\mathrm{T}$ & $9 / 10(90 \%)$ & $8 / 9(88.9 \%)$ & $1 / 8(12.5 \%)$ \\
\hline 2009 & Maranki et al. [12] & 35 & Both & Sb (mostly) & $24 \mathrm{R} ; 3 \mathrm{~T} ; 2 \mathrm{~A}$ & $29 / 35(83 \%)$ & $29 / 35(83 \%)$ & $5 / 35(14.3 \%)$ \\
\hline 2009 & Horaguchi et al. [14] & 7 & M & $\mathrm{Sb}$ & $\mathrm{T}$ & 7/7 (100\%) & $6 / 7(86 \%)$ & $1 / 7(14.3 \%)$ \\
\hline 2011 & Park do et al. [11] & 31 & Both & $\mathrm{Sm}$ & $\mathrm{T}$ & $31 / 31(100 \%)$ & $27 / 31(87 \%)$ & $5 / 31(16 \%)$ \\
\hline 2011 & Weilert et al. [39] & 6 & B & $\mathrm{n} / \mathrm{a}$ & $4 \mathrm{~A} ; 2 \mathrm{R}$ & $6 / 6(100 \%)$ & 6/6 (100\%) & $1 / 6(17 \%)$ \\
\hline \multirow[t]{2}{*}{2012} & Iwashita et al. [36] & 9 & Both & $\mathrm{Sm}$ & $\mathrm{R}$ & $4 / 9(44 \%)$ & $4 / 4(100 \%)$ & $1 / 9(11 \%)$ \\
\hline & Total & 123 & & & $63 \mathrm{~T} ; 46 \mathrm{R} ; 6 \mathrm{~A}$ & $109 / 123(88.6 \%)$ & $103 / 109(94.5 \%)$ & 19/123 (15\%) \\
\hline
\end{tabular}

EUS-CP: endoscopic-ultrasound-guided cholangiopancreatography, $N$ : number of patients, B: benign, M: malignant, Sb: subsequent day, Sm: same day/session, D: ductography, T: transluminal, R: rendezvous, A: antegrade, n/a: not applicable/mentioned. ${ }^{*}$ In few cases stents might have been placed antegrade. ${ }^{\#} 10$ interventions in 8 patients.

range $50-100 \%)$, respectively. The overall complication rates were $19 / 115(16.5 \%$, range $10-42.9 \%)$. These included pancreatitis (mild), abdominal pain, bleed, perforation, fever, severe pancreatitis, and even peripancreatic abscess [8]. Although there was no procedure-related mortality, severe complications (as previously mentioned) were noted with pancreatic drainage via EUS-CP. It is believed that EUSguided pancreatic drainage is usually successful with dilated PD ( $\geq 4 \mathrm{~mm})$, and complications are more likely with nondilated $\mathrm{PD}[8,23]$. The total procedure timings were reported by François et al. [24] in four cases: average 81.25 minutes (range 40-180). In the largest single-operator and singlesession EUS-CP study by Shah et al. [9], the mean procedure time including failed ERCP was only 97 minutes (range 36-210) for both biliary and pancreatic cases. Pancreatic stent types used were plastic (5-10 Fr, straight, single or double pigtail). In the largest reported pancreatic series by Tessier et al. [22], stent dysfunction was noted in 22/36 (55\%) cases. The median stent patency was 195 days (range 10-780). 
TABLE 4: Published EUS-CP series on pancreatic duct drainage (involving $\geq 5$ patients).

\begin{tabular}{|c|c|c|c|c|c|c|c|c|}
\hline Year & Author & $N$ & Indication & Initial ERCP & Techniques & Technical success & Clinical success & Complications \\
\hline 2007 & Will et al. [16] & $12^{*}$ & B & $\mathrm{Sb}$ & $5 \mathrm{~T} ; 4 \mathrm{R}$ & $8 / 12(67 \%)$ & $4 / 8(50 \%)$ & $6 / 14(42.9 \%)$ \\
\hline 2007 & Tessier et al. [22] & 36 & B & $\mathrm{Sb}$ & $\mathrm{T}$ & $33 / 36(91.7 \%)$ & $25 / 36(69 \%)$ & $5 / 36(13.8 \%)$ \\
\hline 2007 & Kahaleh et al. [40] & 13 & B & $\mathrm{Sb}$ & $5 \mathrm{R} ; 5 \mathrm{~T}$ & $10 / 13(77 \%)$ & $10 / 10(100 \%)$ & $2 / 13(15.4 \%)$ \\
\hline 2009 & Brauer et al. [13] & 8 & B & $\mathrm{Sb}$ & $4 \mathrm{~T} ; 3 \mathrm{R}$ & $7 / 8(88 \%)$ & $4 / 8(50 \%)$ & No \\
\hline 2010 & Barkay et al. [8] & 21 & B & $\mathrm{Sb}$ & $6 \mathrm{D}$ (mb injection); $4 \mathrm{R}$ & $10 / 21(48 \%)$ & $8 / 8^{\#}(100 \%)$ & $2 / 21(10 \%)$ \\
\hline \multirow[t]{2}{*}{2012} & Shah et al. [9] & 25 & $\mathrm{~B}$ & $\mathrm{Sm}$ & $10 \mathrm{~A}$ or T; $9 \mathrm{R} ; 3 \mathrm{D}$ & $22 / 25 \%(88 \%)$ & $\mathrm{n} / \mathrm{a}$ & $4 / 25(16 \%)$ \\
\hline & Total & 115 & & & $46 \mathrm{~T} ; 25 \mathrm{R} ; 10 \mathrm{~A} ; 9 \mathrm{D}$ & $90 / 115(78 \%)$ & $51 / 68(75 \%)$ & $19 / 115(16.5 \%)$ \\
\hline
\end{tabular}

EUS-CP: endoscopic-ultrasound-guided cholangiopancreatography, $N$ : number of patients, B: benign, Sb: subsequent day, Sm: same day/session, $\mathrm{D}$ : ductography, T: transluminal, R: rendezvous, A: antegrade, mb: methylene blue, n/a: not applicable/mentioned. ${ }^{*} 14$ attempts in 12 patients. ${ }^{*}$ Long-term data was available in 8 patients only.

\section{Clinical Role of EUS-CP}

At present, EUS-CP is increasingly been used at expert centers as an alternative to surgery or PTC. It should be considered in patients in whom ERCP has failed by an experienced endoscopist, and there is a need for pancreatobiliary drainage. Unlike PTC, EUS-CP can also be performed in patients with ascites [25]. However, only the left intrahepatic biliary tree can be accessed. For isolated right-sided biliary obstruction, PTC is still needed. Although suggested by Dhir et al. [26] in a retrospective nonrandomized study that EUS-guided rendezvous was a low-risk alternative to precut sphincterotomy for biliary cannulation, EUS-CP is a technically challenging procedure with a significant learning curve. The endoscopist should be proficient in both EUS and ERCP. Unlike pancreatic pseudocyst drainage, there is possibility of displacement between the puncture site and obstructed ducts with resultant failure and complications. The creation or dilation of fistula tract may be difficult due to fibrosis as in chronic pancreatitis. Care should be taken to avoid major vessels in the vicinity, like portal vein, hepatic artery, and splenic vessels. However, with increasing availability of endoscopists trained in both ERCP and EUS, the role of EUS-CP is likely to grow in clinical practice.

Same session EUS-CP as failed initial ERCP is practical and may result in avoidance of additional procedures. Combined duodenal and EUS-guided biliary stenting has also been shown to be practical [27]. Although nondilated ducts have been accessed, the puncture can be risky in such cases. The diameter of the working channel of the linear echoendoscopes is still limited, allowing small-caliber stents or delivery systems. There are no dedicated EUS$\mathrm{CP}$ accessories. Commercially available one-step devices are needed. There are no studies directly comparing EUS-CP versus PTC.

\section{Summary}

EUS-CP is safe, efficacious, and a viable alternative to PTC or surgery in failed ERCP cases by an experienced endoscopist. It can be accomplished in one of the four ways: ductography, rendezvous, antegrade, or transluminal stenting. The overall technical and clinical success rates are around $90 \%$ for biliary tree and $70 \%$ for pancreatic duct drainage. The technical success rate is relatively low for pancreatic as compared to biliary cases. The overall EUS-CP complication rate was around $15 \%$. Most of the complications are minor. However, severe complications can be encountered during pancreatic drainage. EUS-CP should be performed by an experienced endoscopist skilled in both EUS and ERCP. EUS-CP has a potential application in benign biliary cases. Same session EUS-CP as failed initial ERCP is practical and may result in avoidance of additional procedures. Since it tends to be a longer procedure, anesthesia support should be sought. Prophylactic antibiotics should be administered to all patients. Future research will be needed to improve instruments and accessories.

\section{Acknowledgment}

This work was supported in part by financial support from Syde Hurdus Foundation Inc., Merrick, NY, USA.

\section{References}

[1] K. Huibregtse and M. B. Kimmey, "Endoscopic retrograde cholangiopancreatography, endoscopic sphincterotomy and endoscopic biliary and pancreatic drainage," in Text Book of Gastroenterology, T. Yamada, Ed., pp. 2590-2617, J. B. Lippincott, Philadelphia, Pa, USA, 1995.

[2] M. Perez-Miranda, C. de la Serna, P. Diez-Redondo, and J. J. Vila, "Endosonography-guided cholangiopancreatography as a salvage drainage procedure for obstructed biliary and pancreatic ducts," World Journal of Gastrointestinal Endoscopy, vol. 2, no. 6, pp. 212-222, 2010.

[3] J. T. Ferrucci Jr., P. R. Mueller, and W. P. Harbin, "Percutaneous transhepatic biliary drainage. Technique, results, and applications," Radiology, vol. 135, no. 1, pp. 1-13, 1980.

[4] O. M. van Delden and J. S. Lameris, "Percutaneous drainage and stenting for palliation of malignant bile duct obstruction," European Radiology, vol. 18, pp. 448-456, 2008.

[5] A. C. Smith, J. F. Dowsett, R. C. G. Russell, A. R. W. Hatfield, and P. B. Cotton, "Randomised trial of endoscopic stenting versus surgical bypass in malignant low bileduct obstruction," Lancet, vol. 344, no. 8938, pp. 1655-1660, 1994.

[6] T. A. Sohn, K. D. Lillemoe, J. L. Cameron, J. J. Huang, H. A. Pitt, and C. J. Yeo, "Surgical palliation of unresectable periampullary adenocarcinoma in the 1990s," Journal of the American College of Surgeons, vol. 188, no. 6, pp. 658-669, 1999. 
[7] M. J. Wiersema, D. Sandusky, R. Carr, L. M. Wiersema, W. C. Erdel, and P. K. Frederick, "Endosonography-guided cholangiopancreatography," Gastrointestinal Endoscopy, vol. 43, no. 2, pp. 102-106, 1996.

[8] O. Barkay, S. Sherman, L. McHenry et al., "Therapeutic EUS-assisted endoscopic retrograde pancreatography after failed pancreatic duct cannulation at ERCP," Gastrointestinal Endoscopy, vol. 71, no. 7, pp. 1166-1173, 2010.

[9] J. N. Shah, F. Marson, F. Weilert et al., "Single-operator, singlesession EUS-guided anterograde cholangiopancreatography in failed ERCP or inaccessible papilla," Gastrointestinal Endoscopy, vol. 75, no. 1, pp. 56-64, 2012.

[10] Y. S. Kim, K. Gupta, S. Mallery, R. Li, T. Kinney, and M. L. Freeman, "Endoscopic ultrasound rendezvous for bile duct access using a transduodenal approach: cumulative experience at a single center. A case series," Endoscopy, vol. 42, no. 6, pp. 496-502, 2010.

[11] H. Park do, J. W. Jang, S. S. Lee, D. W. Seo, S. K. Lee, and M. H. Kim, "EUS-guided biliary drainage with transluminal stenting after failed ERCP: predictors of adverse events and long-term results," Gastrointestinal Endoscopy, vol. 74, no. 6, pp. 1276-1284, 2011.

[12] J. Maranki, A. J. Hernandez, B. Arslan et al., "Interventional endoscopic ultrasound-guided cholangiography: longterm experience of an emerging alternative to percutaneous transhepatic cholangiography," Endoscopy, vol. 41, no. 6, pp. 532-538, 2009.

[13] B. C. Brauer, Y. K. Chen, N. Fukami, and R. J. Shah, "Single-operator EUS-guided cholangiopancreatography for difficult pancreaticobiliary access (with video)," Gastrointestinal Endoscopy, vol. 70, no. 3, pp. 471-479, 2009.

[14] J. Horaguchi, N. Fujita, Y. Noda et al., "Endosonography-guided biliary drainage in cases with difficult transpapillary endoscopic biliary drainage: original article," Digestive Endoscopy, vol. 21, no. 4, pp. 239-244, 2009.

[15] O. Barkay, S. Sherman, L. McHenry et al., "Therapeutic EUS-assisted endoscopic retrograde pancreatography after failed pancreatic duct cannulation at ERCP," Gastrointestinal Endoscopy, vol. 71, no. 7, pp. 1166-1173, 2010.

[16] U. Will, F. Fueldner, A. K. Thieme et al., "Transgastric pancreatography and EUS-guided drainage of the pancreatic duct," Journal of Hepato-Biliary-Pancreatic Surgery, vol. 14, no. 4, pp. 377-382, 2007.

[17] M. Kahaleh, A. J. Hernandez, J. Tokar, R. B. Adams, V. M. Shami, and P. Yeaton, "EUS-guided pancreaticogastrostomy: analysis of its efficacy to drain inaccessible pancreatic ducts," Gastrointestinal Endoscopy, vol. 65, no. 2, pp. 224-230, 2007.

[18] M. Giovannini, V. Moutardier, C. Pesenti, E. Bories, B. Lelong, and J. R. Delpero, "Endoscopic ultrasound-guided bilioduodenal anastomosis: a new technique for biliary drainage," Endoscopy, vol. 33, no. 10, pp. 898-900, 2001.

[19] A. Püspök, F. Lomoschitz, C. Dejaco, M. Hejna, T. Sautner, and A. Gangl, "Endoscopic ultrasound guided therapy of benign and malignant biliary obstruction: a case series," American Journal of Gastroenterology, vol. 100, no. 8, pp. 1743-1747, 2005.

[20] T. H. Kim, S. H. Kim, H. J. Oh, Y. W. Sohn, and S. O. Lee, "Endoscopic ultrasound-guided biliary drainage with placement of a fully covered metal stent for malignant biliary obstruction," World Journal of Gastroenterology, vol. 18, no. 20, pp. 2526-2532, 2012.

[21] J. DeWitt, L. McHenry, E. Fogel, J. LeBlanc, K. McGreevy, and S. Sherman, "EUS-guided methylene blue pancreatography for minor papilla localization after unsuccessful ERCP," Gastrointestinal Endoscopy, vol. 59, no. 1, pp. 133-136, 2004.

[22] G. Tessier, E. Bories, M. Arvanitakis et al., "EUS-guided pancreatogastrostomy and pancreatobulbostomy for the treatment of pain in patients with pancreatic ductal dilatation inaccessible for transpapillary endoscopic therapy," Gastrointestinal Endoscopy, vol. 65, no. 2, pp. 233-241, 2007.

[23] S. Mallery, J. Matlock, and M. L. Freeman, "EUS-guided rendezvous drainage of obstructed biliary and pancreatic ducts: report of 6 cases," Gastrointestinal Endoscopy, vol. 59, no. 1, pp. 100-107, 2004.

[24] E. François, M. Kahaleh, M. Giovannini, C. Matos, and J. Devière, "EUS-guided pancreaticogastrostomy," Gastrointestinal Endoscopy, vol. 56, no. 1, pp. 128-133, 2002.

[25] T. L. Ang, E. K. Teo, and K. M. Fock, "EUS-guided transduodenal biliary drainage in unresectable pancreatic cancer with obstructive jaundice," Journal of the Pancreas, vol. 8, no. 4, pp. 438-443, 2007.

[26] V. Dhir, S. Bhandari, M. Bapat, and A. Maydeo, "Comparison of EUS-guided rendezvous and precut papillotomy techniques for biliary access," Gastrointestinal Endoscopy, vol. 75, no. 2, pp. 354-359, 2012.

[27] M. Iwamuro, H. Kawamoto, R. Harada et al., "Combined duodenal stent placement and endoscopic ultrasonographyguided biliary drainage for malignant duodenal obstruction with biliary stricture," Digestive Endoscopy, vol. 22, no. 3, pp. 236-240, 2010.

[28] M. Kahaleh, A. J. Hernandez, J. Tokar, R. B. Adams, V. M. Shami, and P. Yeaton, "Interventional EUS-guided cholangiography: evaluation of a technique in evolution," Gastrointestinal Endoscopy, vol. 64, no. 1, pp. 52-59, 2006.

[29] K. Yamao, V. Bhatia, N. Mizuno et al., "EUS-guided choledochoduodenostomy for palliative biliary drainage in patients with malignant biliary obstruction: results of long-term followup," Endoscopy, vol. 40, no. 4, pp. 340-342, 2008.

[30] I. Tarantino, L. Barresi, A. Repici, and M. Traina, "EUS-guided biliary drainage: a case series," Endoscopy, vol. 40, no. 4, pp. 336339, 2008.

[31] A. A. Siddiqui, J. Sreenarasimhaiah, L. F. Lara, W. Harford, C. Lee, and M. A. Eloubeidi, "Endoscopic ultrasound-guided transduodenal placement of a fully covered metal stent for palliative biliary drainage in patients with malignant biliary obstruction," Surgical Endoscopy and Other Interventional Techniques, vol. 25, no. 2, pp. 549-555, 2011.

[32] T. Komaki, M. Kitano, H. Sakamoto, and M. Kudo, "Endoscopic ultrasonography-guided biliary drainage: evaluation of a choledochoduodenostomy technique," Pancreatology, vol. 11, no. 2, supplement, pp. 47-51, 2011.

[33] K. Hara, K. Yamao, Y. Niwa et al., "Prospective clinical study of EUS-guided choledochoduodenostomy for malignant lower biliary tract obstruction," American Journal of Gastroenterology, vol. 106, no. 7, pp. 1239-1245, 2011.

[34] M. A. Ramírez-Luna, F. I. Téllez-Ávila, M. Giovannini, F. Valdovinos-Andraca, I. Guerrero-Hernández, and J. HerreraEsquivel, "Endoscopic ultrasound-guided biliodigestive drainage is a good alternative in patients with unresectable cancer," Endoscopy, vol. 43, no. 9, pp. 826-830, 2011.

[35] C. Fabbri, C. Luigiano, L. Fuccio et al., "EUS-guided biliary drainage with placement of a new partially covered biliary stent for palliation of malignant biliary obstruction: a case series," Endoscopy, vol. 43, no. 5, pp. 438-441, 2011. 
[36] T. Iwashita, J. G. Lee, S. Shinoura et al., "Endoscopic ultrasoundguided rendezvous for biliary access after failed cannulation," Endoscopy, vol. 44, no. 1, pp. 60-65, 2012.

[37] F. Maluf-Filho, F. A. Retes, C. Z. Neves et al., "Transduodenal endosonography-guided biliary drainage and duodenal stenting for palliation of malignant obstructive jaundice and duodenal obstruction," Journal of the Pancreas, vol. 13, no. 2, pp. 210-214, 2012.

[38] E. Bories, C. Pesenti, F. Caillol, C. Lopes, and M. Giovanni, "Transgastric endoscopic ultrasonography-guided biliary drainage: results of a pilot study," Endoscopy, vol. 39, no. 4, pp. 287-291, 2007.

[39] F. Weilert, K. F. Binmoeller, F. Marson, Y. Bhat, and J. N. Shah, "Endoscopic ultrasound-guided anterograde treatment of biliary stones following gastric bypass," Endoscopy, vol. 43, no. 12, pp. 1105-1108, 2011.

[40] M. Kahaleh, A. J. Hernandez, J. Tokar, R. B. Adams, V. M. Shami, and P. Yeaton, "EUS-guided pancreaticogastrostomy: analysis of its efficacy to drain inaccessible pancreatic ducts," Gastrointestinal Endoscopy, vol. 65, no. 2, pp. 224-230, 2007. 


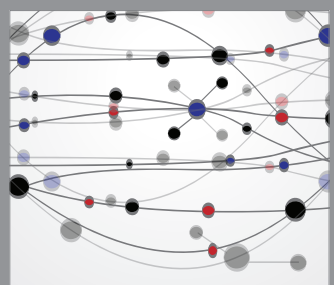

The Scientific World Journal
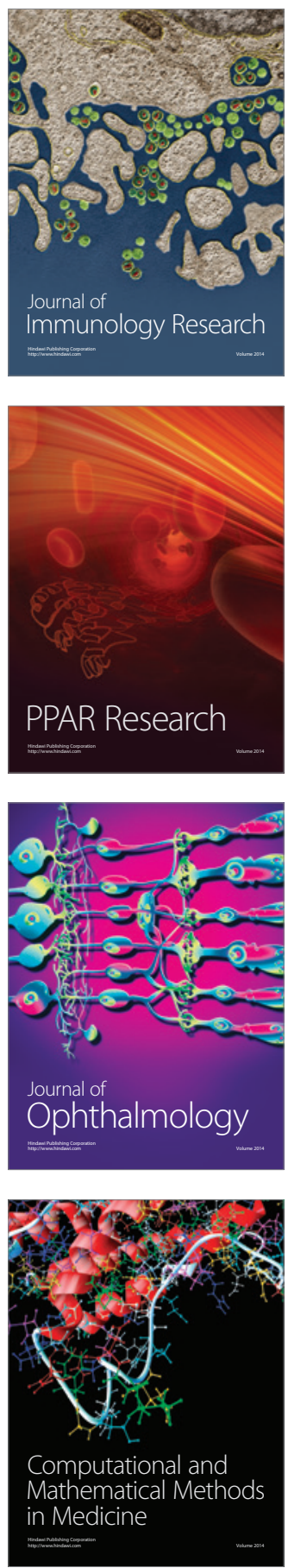

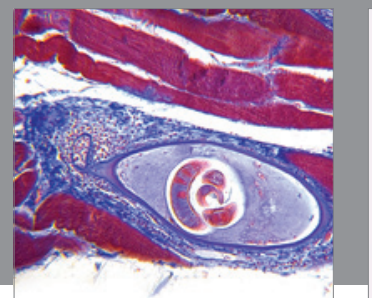

Gastroenterology

Research and Practice
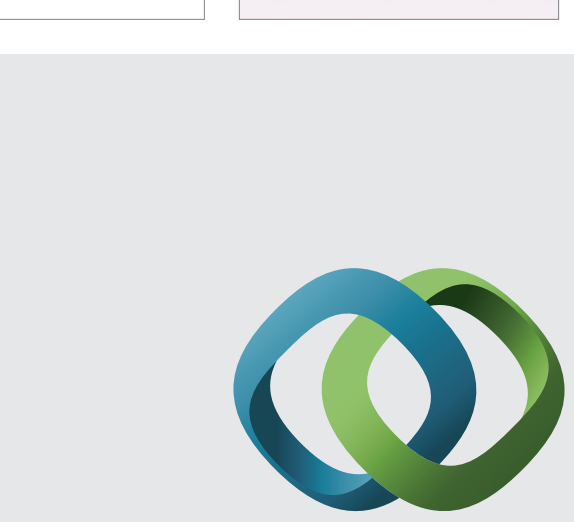

\section{Hindawi}

Submit your manuscripts at

http://www.hindawi.com
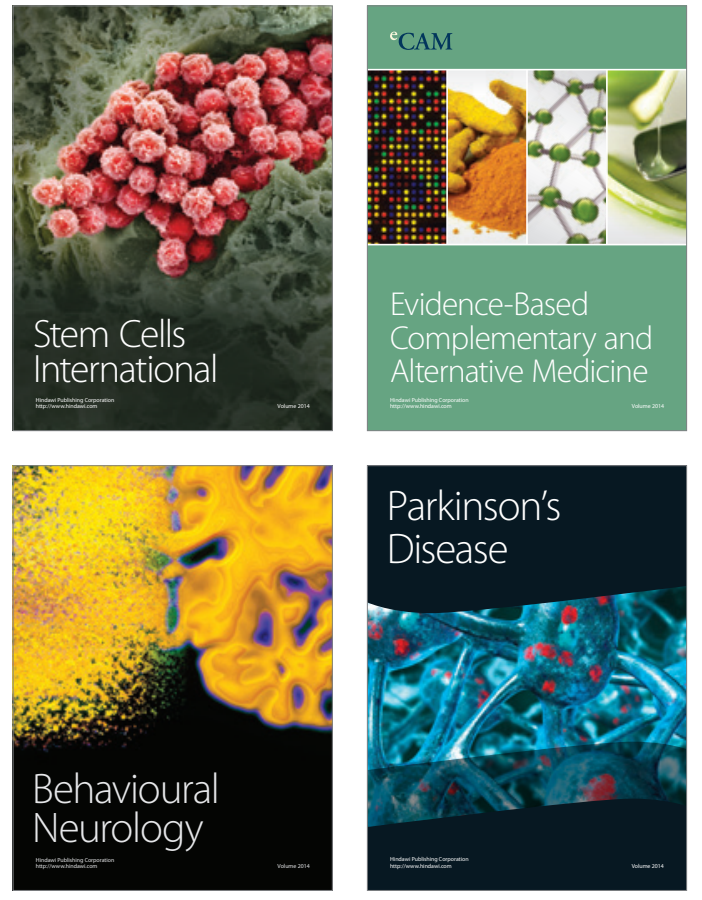
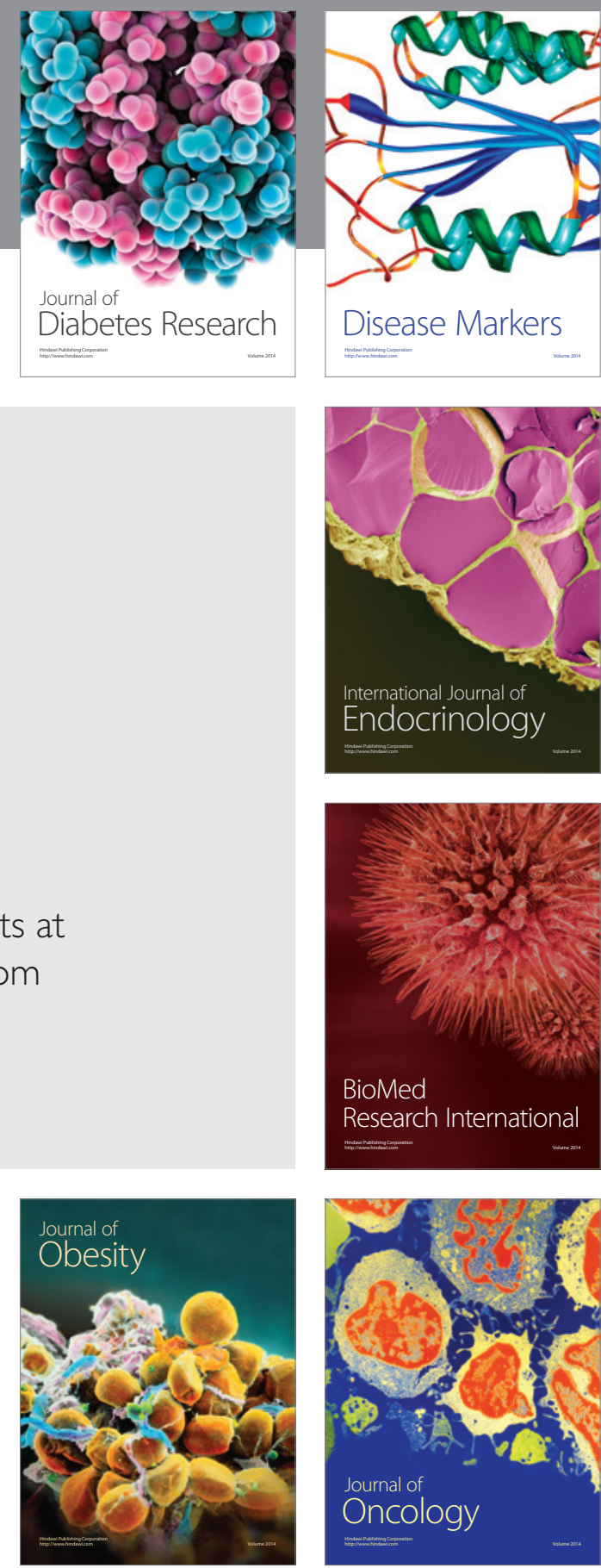

Disease Markers
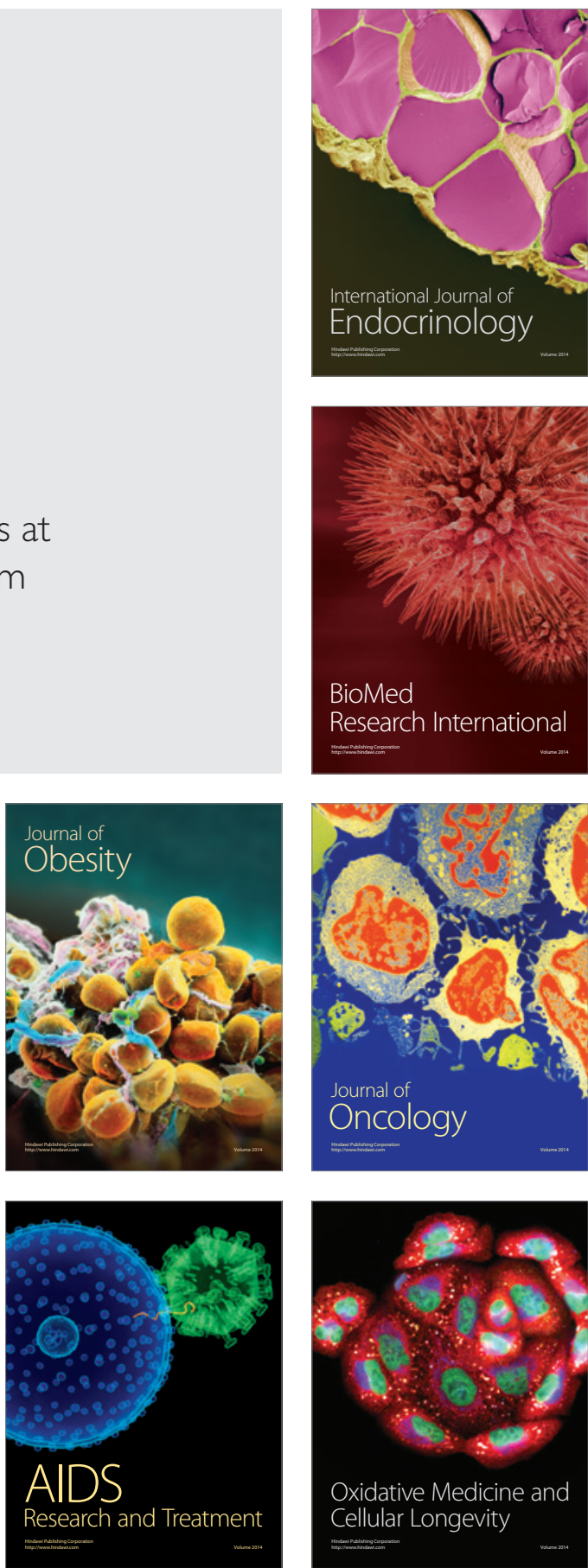